\title{
Reproductive aspects of Chagas disease vectors (Hemiptera, Triatominae) with anatomical teratologies
}

\author{
Kaio Cesar Chaboli Alevi ${ }^{\mathrm{a}, \mathrm{b}, *}$, Yuri Augusto ${ }^{\mathrm{a}}$, Jader de Oliveira ${ }^{\mathrm{c}}$, Tiago Belintani ${ }^{\mathrm{c}}$, \\ Lucas Abrantes da Silva ${ }^{c}$, João Aristeu da Rosa ${ }^{c}$, Maria Tercília Vilela Azeredo-Oliveira ${ }^{a}$ \\ a Departamento de Biologia, Instituto de Biociências, Letras e Ciências Exatas, Universidade Estadual Paulista “Júlio de Mesquita Filho"-IBILCE/UNESP, Rua Cristóvão \\ Colombo, 2265, 15054-000, São José do Rio Preto, SP, Brazil \\ b Departamento de Biologia e Zootecnia, Faculdade de Engenharia de Ilha Solteira, Universidade Estadual Paulista "Júlio de Mesquita Filho"-FEIS/UNESP, Avenida \\ Brasil, 56, 15385-000, Ilha Solteira, SP, Brazil \\ ${ }^{\mathrm{c}}$ Departamento de Ciências Biológicas, Faculdade de Ciências Farmacêticas, Universidade Estadual Paulista “Júlio de Mesquita Filho", FCFAR/UNESP, Rodovia \\ Araraquara-Jaú km 1, 14801-902, Araraquara, SP, Brazil
}

\section{A R T I C L E I N F O}

\section{Keywords:}

Spermatogenesis

Gonadal dysgenesis

Morphological abnormalities

Triatomines

\begin{abstract}
A B S T R A C T
As Chagas disease has no cure, vector control is the most effective method of preventing this neglected disease. Generally the anatomical teratologies are associated with hormonal dysfunction of the corpus allatum (juvenile hormone), presents genetic basis or unfavorable conditions, and are recessive and not sex linked. Thus, we characterize the male gonads and spermatogenesis of triatomines with anatomical teratologies to evaluate if the malformations interfere in the gametogenesis of these vectors. All teratogenic triatomines analyzed did not present presented gonadal dysgenesis and alterations in spermatogenesis. Thus, we characterize the presence of anatomical teratologies in some species of triatomines and demonstrate that these malformations in the external morphology do not interfere in the gonads and gametogenesis of these vectors. In addition, although new studies with the corpus allatum should be conducted we suggesting that the use of juvenile hormones does not present effectiveness in the reproductive control of these vectors.
\end{abstract}

Chagas disease is a neglected disease distributed in endemic areas of 21 Latin American countries caused by the protozoan Trypanosoma cruzi and transmitted to humans mainly by contact with feces of triatomines (WHO, 2015). Currently, there are 152 species of triatomines, distributed in 18 genera and five tribes, being all species considered as potential vector of Chagas disease (Justi and Galvão, 2017; Oliveira and Alevi, 2017).

As Chagas disease has no cure and treatment is effective only in the acute phase of the disease (which is often asymptomatic), vector control is the most effective method of preventing this neglected disease (WHO, 2015). Thus, all knowledge about these hematophagous insects is important and can generate subsidies to assist the vector control programs.

Anatomical studies of the triatomines are common and have contributed to the taxonomic, systematic and evolutionary knowledge of the vectors (Pinto, 1927; Galvão, 2014). However, little is known about anatomical teratologies in the subfamily Triatominae, being the majority of studies performed in Triatoma infestans (Carcavallo, 1967; Juárez, 1972; Carcavallo and Galíndez Girón, 1995; Jurberg et al.,
1997). The teratologies are present in the structures of the head, thorax and abdomen of triatomines (Carcavallo et al., 1998).

Although the teratologies of the triatomines generally are associated with hormonal dysfunction of the corpus allatum (responsible for producing juvenile hormone) (Juárez, 1972), the causes of their occurrence are very diverse (genetic basis or unfavorable conditions of the breeding environment), as described by Ryckman (1971). Triatomines exposed to 9-cis-retinoic acid (9cisRA) or juvenile hormone underwent profound morphological changes upon moult, generating abnormal 5th instar nymphs and also markedly increased the death of insects during the moulting (Nakamura et al., 2007). Ryckman (1971) performed experimental crosses between teratogenic $T$. protracta and described the teratologies as recessive and not sex linked.

Thus, in order to contribute to the knowledge of these insects of importance to public health, we characterize the male gonads and spermatogenesis of triatomines with anatomical teratologies to evaluate if the malformations interfere in the gametogenesis of these vectors.

Were analyzed at least two adult male specimens of each species ( $T$. costalimai, T. garciabesi, T. guasayana, T. infestans, T. juazeirensis, T.

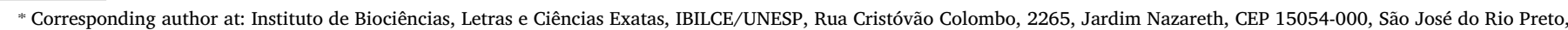
SP, Brazil.

E-mail address: kaiochaboli@hotmail.com (K.C.C. Alevi). 

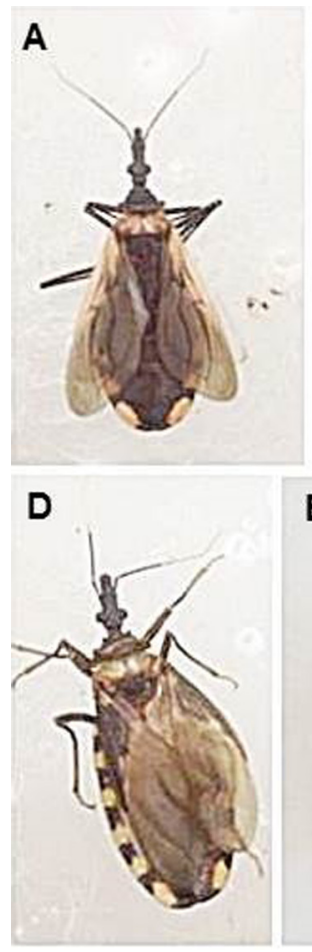

B

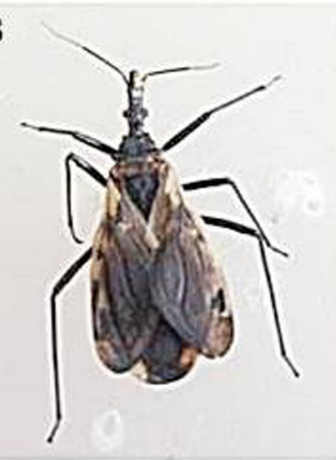

E

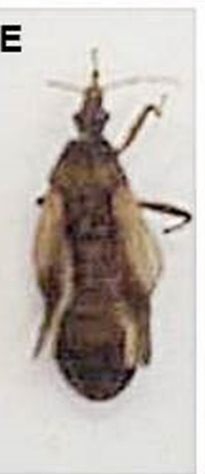

C

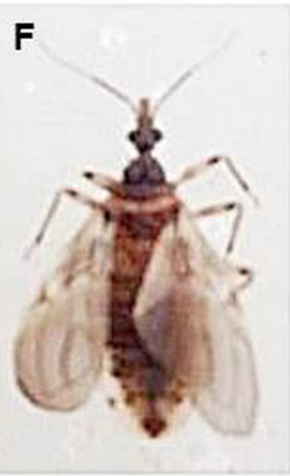

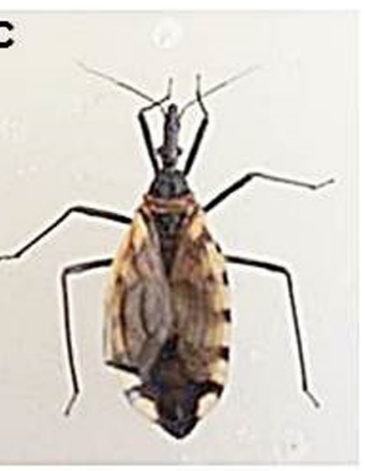

G

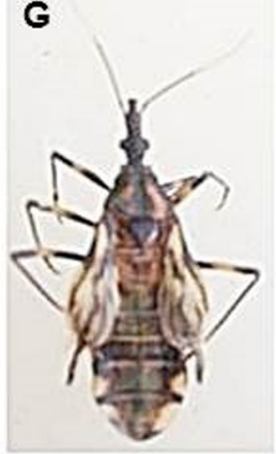

Fig. 1. Examples of anatomical teratologies in triatomines: (A) T. klugi, (B) T. rubrovaria, (C) T. pseudomaculata, (D) T. infestans, (E) P. tertius, (F) T. guasayana and (G) T. brasiliensis. Note the presence of teratology in the wings of all species (A-G), as well as in the thorax of T. klugi (A) and T. pseudomaculata (D) and in the abdomen of P. tertius (E) and T. brasiliensis $(G)$.

Table 1

Teratologies described in triatomines.

\begin{tabular}{|c|c|c|}
\hline Triatomines & Teratologies & References \\
\hline Triatoma brasiliensis & abdomen, wings and legs (tibia) & Carcavallo et al. (1998) \\
\hline Triatoma breyeri & thorax (pronotum) & Carcavallo et al. (1998) \\
\hline Triatoma costalimai & wings & First description \\
\hline Triatoma garciabesi & wings & First description \\
\hline Triatoma guasayana & wings & First description \\
\hline Triatoma infestans & $\begin{array}{l}\text { wings (corium), legs (tibiae and tarsi), head (ocellar and antenna), thorax (pronotum, } \\
\text { mesonotum, metanotum and propleura), adultoids (treatment of anti-juvenile hormonal } \\
\text { compound) }\end{array}$ & $\begin{array}{l}\text { Carcavallo (1967); Juárez (1972), Carcavallo and } \\
\text { Galíndez Girón (1995), Jurberg et al. (1997) }\end{array}$ \\
\hline Triatoma juazeirensis & legs and wings & First description \\
\hline Triatoma klugi & wings and thorax & First description \\
\hline Triatoma lecticularia & legs and thorax & First description \\
\hline Triatoma lenti & legs and wings & First description \\
\hline Triatoma maculata & abdomen and wings & Carcavallo et al. (1998) \\
\hline Triatoma patagonica & thorax (mesonotum and metanotum) and wings & Carcavallo et al. (1998) \\
\hline Triatoma protracta & thorax (pronotum and mesonotum), wings and genital & Ryckman (1971) \\
\hline Triatoma pseudomaculata & wings & First description \\
\hline Triatoma rubida & legs (an oligomery with unilateral atrophy in the left mesothoracic) & Faúndez and Ayala (2017) \\
\hline Triatoma rubrovaria & wings & First description \\
\hline Triatoma sordida & wings & Carcavallo et al. (1998) \\
\hline Triatoma vitticeps & legs and wings & First description \\
\hline Panstrongylus megistus & adultoids (treatment of anti-juvenile hormonal compound) & Jurberg et al. (1982) \\
\hline Psammolestes coreodes & legs and thorax & First description \\
\hline Psammolestes tertius & abdomen and wings & First description \\
\hline Panstrongylus humeralis & legs (a unilateral atrophy on the right metathoracic) & Faúndez and Ayala (2017) \\
\hline Rhodnius brethesi & legs and wings & First description \\
\hline Rhodnius ecuadoriensis & wings & Carcavallo et al. (1998) \\
\hline Rhodnius neglectus & legs & First description \\
\hline Rhodnius pictipes & legs & First description \\
\hline \multirow[t]{2}{*}{ Rhodnius prolixus } & legs and wings & First description \\
\hline & adultoids (treatment of anti-juvenile hormonal compound) & Jurberg et al. (1997) \\
\hline Rhodnius robustus & legs (femur and tibia) and wings corium & Carcavallo et al. (1998) \\
\hline
\end{tabular}

klugi, T. lecticularia, T. lenti, T. pseudomaculata, T. rubrovaria, T. vitticeps, Psammolestes coreodes, P. tertius, Rhodnius brethesi, R. neglectus, R. pictipes and $R$. prolixus) provided by the "Insetário de Triatominae", from FCFAR/UNESP, Araraquara, São Paulo, Brazil. The selection of triatomines occurred based on the presence of anatomical teratologies. The insects were dissected, the testicles were removed, and examined by stereoscope microscope for analysis of gonadal dysgenesis (unilateral or bilateral dysgenesis) (Almeida and Carareto, 2002). Posteriorly, the seminiferous tubules were shredded, smashed, set on a slide in liquid nitrogen and stained with lactic acetic orcein (De Vaio et al., 1985; Alevi et al., 2012) for analysis of spermatogenesis.

Some species were selected to represent the anatomical teratologies 

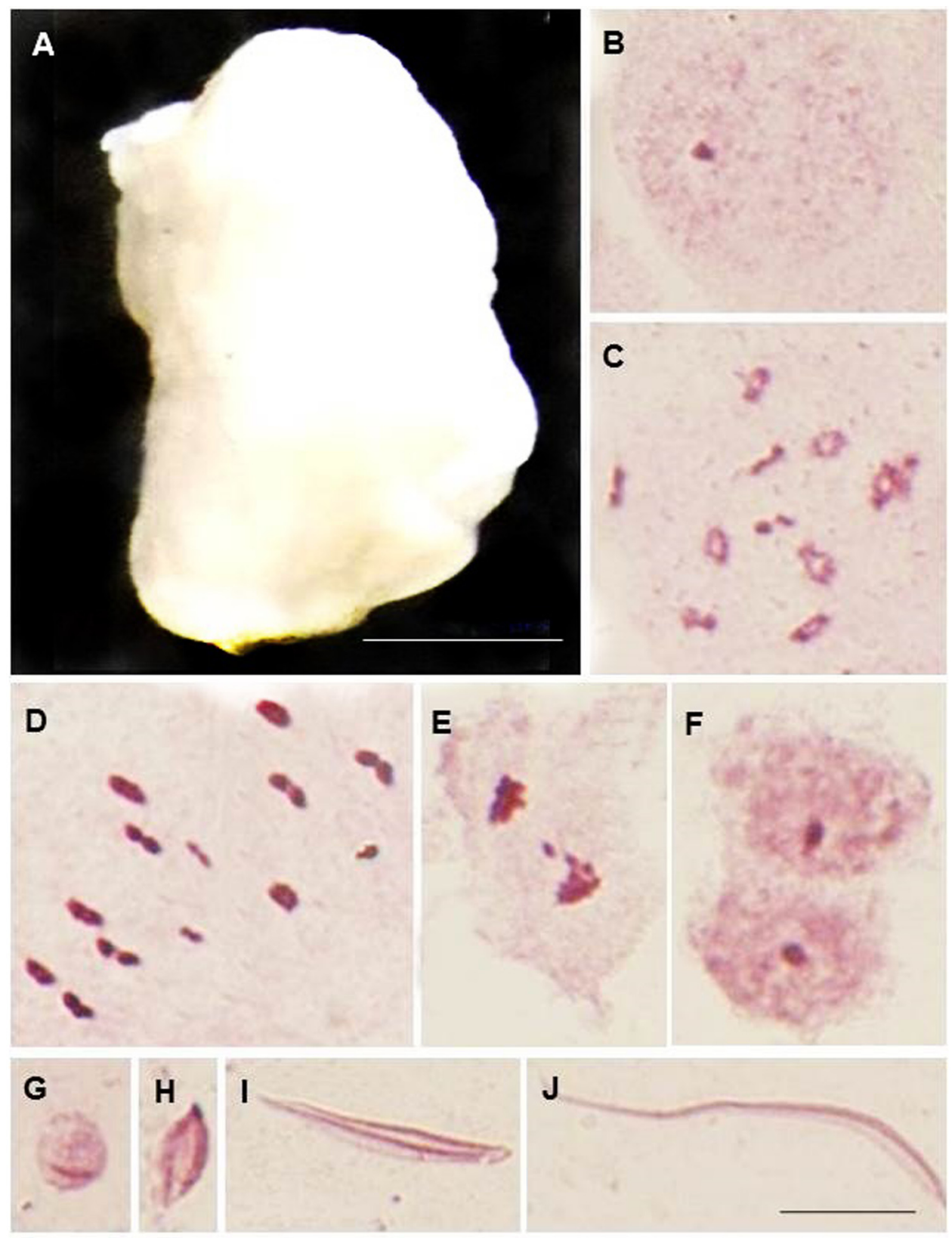

Fig. 2. Testis and spermatogenesis of T. rubrovaria. (A) Normal testis. Bar: $10 \mathrm{~mm}$. (B, C) Prophase. (D) Metaphase. (E) Anaphase. (F) Telophase. (G-J) Spermiogenesis. Bar: $10 \mu \mathrm{m}$.

(Fig. 1). All triatomines analyzed presented teratologies in the wings (Table 1, Fig. 1A-G). In addition, malformations in the thorax (Table 1, Fig. 1A, D) and abdomen (Table 1, Fig. 1E, G) were also observed. On the other hand, none of these triatomines presented gonadal dysgenesis and alterations in spermatogenesis [represented by the gonad (Fig. 2A) and spermatogenesis (Fig. 2B-J) of T. rubrovaria].

These results demonstrate that triatomines with anatomical teratologies do not present gonadal dysgenesis and alterations in gametogenesis. Although the fertility reduction may be related to other factors, such as inability to transfer sperm to the female's spermathecal (Perlowagora-Szumlewicz and Correia, 1972), or the existence of essential secretions for sperm migration to the female receptacle (Schreiber et al., 1975), we demonstrated for the first time that the formation of gametes in teratogenic occurs normally, corroborating the results of Ryckman (1971).

The use of products analogous to juvenile hormones was initially associated with the control of triatomines in domiciliary regions
(Pinchin et al., 1978; Carcavallo et al., 1998). Several studies with these analogues have demonstrated that the application leads to anatomical teratologies and the formation of adultoids (Table 1). Considering the hypothesis that the anatomical changes come only from problems in the corpus allatum and consequently in the rates of juvenile hormone, the crosses performed by Ryckman (1971) in conjunction with the reproductive aspects described here demonstrated that males triatomines with anatomical teratologies present reproductive fitness, suggesting that the use of juvenile hormones does not present effectiveness in the reproductive control of these vectors. However, further studies should be performed with this structure to determine whether triatomine teratogens are exclusively associated with hormonal dysfunction or if there are other influences, as already mentioned above.

Thus, we characterize the presence of anatomical teratologies in some species of triatomines and demonstrate that these malformations in the external morphology do not interfere in the gonads and gametogenesis of these vectors. In addition, although new studies with the 
corpus allatum should be conducted (to confirm its direct relationship with the teralogies), suggesting that the use of juvenile hormones does not present effectiveness in the reproductive control of these vectors.

\section{Ethical standards}

The experiments comply with the current laws of the country in which they were performed.

\section{Conflict of interest}

The authors declare that they have no conflict of interest.

\section{Acknowledgments}

The study was supported by Fundação de Amparo à Pesquisa do Estado de São Paulo (Process numbers 2013/19764-0) and Conselho Nacional de Desenvolvimento Científico e Tecnológico (CNPq, Brazil).

\section{References}

Alevi, K.C.C., Mendonça, P.P., Pereira, N.P., Rosa, J.A., Azeredo-Oliveira, M.T.V., 2012. Karyotype of Triatoma melanocephala Neiva and Pinto (1923). Does this species fit in the Brasiliensis subcomplex? Infect. Genet. Evol. 12, 1652-1653.

Almeida, L.M., Carareto, C.M.A., 2002. Gonadal hybrid dysgenesis in Drosophila sturtevanti (Diptera, Drosophilidae). Ilheringia 92, 71-79.

Carcavallo, R.U., 1967. Teratologias en Triatoma infestans (Klug). Seg. Jorn. Entomoepidemiol. Arg. 111, 89-90.

Carcavallo, R.U., Galíndez Girón, I., 1995. Algunas interesantes teratologías en Triatoma infestans (Klug. Entomol. Vect. 2, 3-8.

Carcavallo, U., Gíron, I.G., Jurberg, J., Galvão, C., Noireau, F., Canale, D.M., 1998 Mutations, hybrids and teratologies. In: Carcavallo, R.U., Galíndez-Girón, I., Jurberg, J., Lent, H. (Eds.), Atlas of Chagas Disease Vectors in the Americas. Editora Fiocruz Press, Rio de Janeiro, pp. 621-664.
De Vaio, E.S., Grucci, B., Castagnino, A.M., Franca, M.E., Martinez, M.E., 1985. Meiotic differences between three triatomine species (Hemiptera:Reduviidae). Genetica 67, 185-191.

Faúndez, E.I., Ayala, J.M., 2017. Descripción de dos anomalías en triatominos (Heteroptera: Reduviidae). Arq. Entomol. 18, 27-30.

Galvão, C., 2014. Vetores da doença de Chagas no Brasil. Sociedade Brasileira de Zoologia, Curitiba, Brasil.

Juárez, E., 1972. Formas anômalas de Triatoma infestans. Rev. Saude Publ. 6, 427-429.

Jurberg, J., Gonçalves, T.C.M., Oliveira Filho, A.M., 1982. Alterações morfológicas provocadas pela aplicação de Precocenc II em Panstrongylus megistus (Burmeister, 18351, (Hemiptera, Reduviidae, Triatominae). Rev. Bras. Biol. 42, 527-538.

Jurberg, J., Galvão, C., Bowers, W.S., Garcia, E.S., Azambuja, P., 1997. Biomorphological alterations induced by an anti-juvenile hormonal compound, 2-(2-EthoxyEthoxy) ethyl furfuryl ether, on three species of Triatominae larvae (Hemiptera Reduviidae). Mem. Inst. Oswaldo Cruz 92, 263-268.

Justi, A.S., Galvão, C., 2017. The evolutionary origin of diversity in Chagas disease vectors. Trends Parasitol. 33, 42-52.

Nakamura, A., Stiebler, R., Fantappié, M.R., Fialho, E., Masuda, H., Oliveira, M.F., 2007. Effects of retinoids and juvenoids on moult and on phenoloxidase activity in the blood-sucking insect Rhodnius prolixus. Acta Trop. 103, 222-230.

Oliveira, J., Alevi, K.C.C., 2017. Taxonomic status of Panstrongylus herreri Wygodzinsky, 1948 and the number of Chagas disease vectors. Rev. Soc. Bras. Med. Trop. 50, 434-435.

Perlowagora-Szumlewicz, A., Correia, M.V., 1972. Introduction of male sterility though manipulation of genetic mechanisms present in vector species of Chagas'disease. Rev. Inst. Med. Trop. São Paulo 14, 360-371.

Pinchin, R., Oliveira Filho, A.M., Figueiredo, M.J., Muller, C.A., Gilbert, B., 1978. Slowrelease juvenile homone formulations for triatomine control. Trans. R. Soc. Trop. Med. Hyg. 72, 322-323.

Pinto, C., 1927. Chave dos gêneros baseada na anatomia do rostro, tórax e inserção das antenas. Bol. Biol. 8, 103-114.

Ryckman, R.E., 1971. A genetic mutation and gross pathologies in populations of the Tratoma protracta superspecies (Hemiptera, Reduviidae, Triatominae). J. Med. Entomol. 8, 111-115.

Schreiber, G., Perlowagora-Szumlewicz, A., Martins, R.P., 1975. Cytogenetics of Triatominae. III: a study on male sterility induced through hybridization of Triatoma sordida and Triatoma pseudomaculata. Rev. Soc. Bras. Med. Trop. 09, 189-195.

World Health Organization, 2015. Chagas disease (American Trypanosomiasis). Week. Epidem. Rec. 90, 33-44. 